\title{
Mobile Cloud Learning Using UML and Feature Driven Development On Higher Education
}

\author{
Kristiawan Nugroho ${ }^{1}$, Sumardi ${ }^{2}$, Sugeng Murdowo ${ }^{3}$ \\ \{kristiawan1979@gmail.com ${ }^{1}$,masmardis@gmail.com ${ }^{2}$,sugengmurdowo0298@gmail.com ${ }^{3}$ \}
}

AMIK Jakarta Teknologi Cipta, Jl. Kelud Raya No 19 Semarang ${ }^{123}$.

\begin{abstract}
Education is one of the priorities of the Indonesian government in improving the quality of human resources. The education system at universities evolved from a simple learning model to a modern learning system. Currently the modern learning system using the support of information technology that is the internet, students and lecturers can not only interact in learning directly in class but can do online lectures using e-learning media. E-learning technology continues to grow today but not all universities can implement this system due to limited hardware and computer network resources. This study designs mobile cloud learning using UML and driven development methods to produce a mobile cloud learning application that can help students learn to use their gadgets or smatphone. This system provides benefits for students in learning anytime and anywhere that will improve the effectiveness of students in learning.
\end{abstract}

Keywords: learning, mobile, cloud, UML.

\section{Introduction}

Students are an important human resource for a country. In Indonesia according to data from PDIKTI in 2018 there are 5,712,038 students consisting of 2,635,747 female male students and 3,076,291 female female students studying at various universities in Indonesia. This great human resource must be well cultivated to produce competent resources in support of state development. Currently, learning in several universities in Indonesia has been using elearning where students and lecturers can interact in the learning process through the internet, but in reality not all universities can implement e-learning due to limited computer and network resources so they can not implement the system this well.

Currently developing technology with the name of cloud computing. Cloud computing is a mechanism in renting the resources of both servers, networks and applications that can be accessed via Internet technology[1]. There are four models in cloud computing: Infrastructure as a Service (IaaS), Platform as a Service (PaaS), Software as a Service (SaaS) and Network as a Service (Naas)[2]. Institution institutions can take advantage of the facilities to support the implementation of e-learning in their respective universities.

Cloud computing technology has helped human life, including health, government, telecommunications and education. In the field of education cloud computing has been instrumental in providing data storage that has a large capacity that can be accessed anytime and anywhere by using the internet. The use of the Internet is a must in this technology, with the support of internet that having higher speed, cloud computing services will also be accessed properly.

ICCSET 2018, October 25-26, Kudus, Indonesia

Copyright (C) 2018 EAI

DOI 10.4108/eai.24-10-2018.2280537 


\section{Related Work}

The rapid development of information technology also lead to an increasingly modern lifestyle of students where they compete to communicate using a smartphone. The use of this smartphone can be directed to the form of a positive activity especially related to learning in college.semakin modern development of these technologies led to the emergence of mobile learning as a new learning model. Mobile learning, sometimes called m-learning, portable computing devices, computing devices may include: smart phones, personal digital assistants (PDAs) and similar handheld devices[3].

Mobile Cloud Learning (MCL) is a concept of learning by using mobile devices such as smartphones, laptops and other mobile devices using cloud computing media in optimizing server resources, aplication and data storage. Research on mobile learning has been conducted by various researchers, the term mobile learning was first introduced around the 1990s as a development of e-learning concept using mobile devices[4]. In addition, research on mobile learning is also done by Ayman Bassam Nassuora, He examines the acceptance rate of the use of mlearning at universities in Saudi Arabia[5]. Learning uses mlearning using wireless communication so that students can access teaching materials anytime, anywhere, and in the classroom[6]. With the learning model with MCL students will be more effective in communicating with lecturers in learning activities so they can learn in the time and place they want.

MCL uses Unified Modeling Language (UML) as an object-based design tool. UML is a standard visual modeling language which is designed for the specifying, visualizing, constructing and documenting of the artifacts of software systems[7]. UML consists of several forms such as use case diagrams, activity diagrams, sequence diagrams and class diagrams. By using UML then a mobile-based application can be designed well from the beginning of the design of the system to the process of making the application, UML is an appropriate method in designing sustainable systems so that applications that will be developed by developers can be well documented. UML is a tool that combines the techniques and processes of data modeling, business modeling, object modeling, and component modeling[8], using UML will help in designing object-based application models well so that the design results will be readily used in building object- mobile.

\section{Method}

Feature Driven Development(FDD) is a method included in AGILE, this method is useful in the development of application software. FDD is a fast and adaptive method of building software. FDD consists of 5 basic stages that form the application in a project where each stage will be marked to know the progress of a project[9], FDD shown in the following figure: 


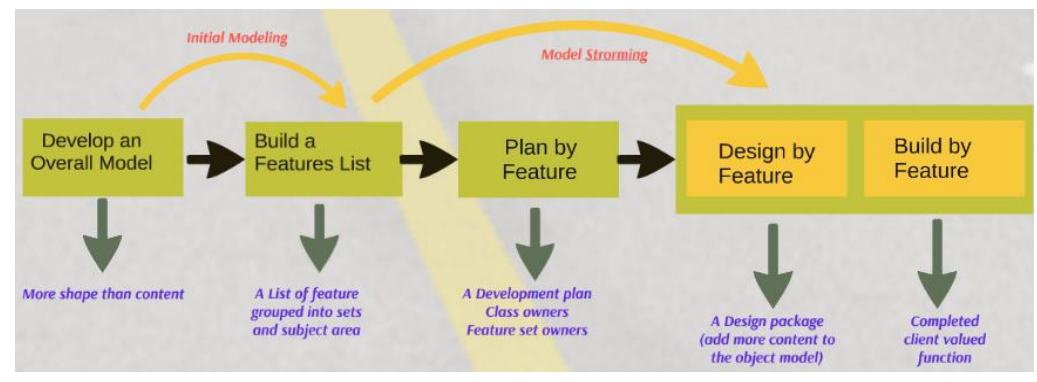

Fig .1. Feature Driven Development Method.

1. Develop an overall model

It is a step in developing the whole model. Here the project team from the business domain is more form than the contents. This model has not been fully defined with all the attributes and methods.

2. Built a feature list

That is a step in making a list of features using the client language the language the client understands) so there is no misunderstanding.

3. Plan by feature

It is a feature plan. In this section the feature is planned what process just what to do.

4. Design by feature

That is the design for the feature-feature will be designed so as to achieve client value.

5. Build by feature

Build by feature is a stage in making various facilities / features to be included in the application in accordance with user / client request according to previous agreement.

\section{Results and Discussion}

MCL design in this paper using UML described in several parts, namely:

\subsection{Use Case Diagram}

Use case diagram is a tool to develop the system by explaining the relationship between the various actors involved in the system. The use case design for MCL is shown in Figure 1 as follows: 


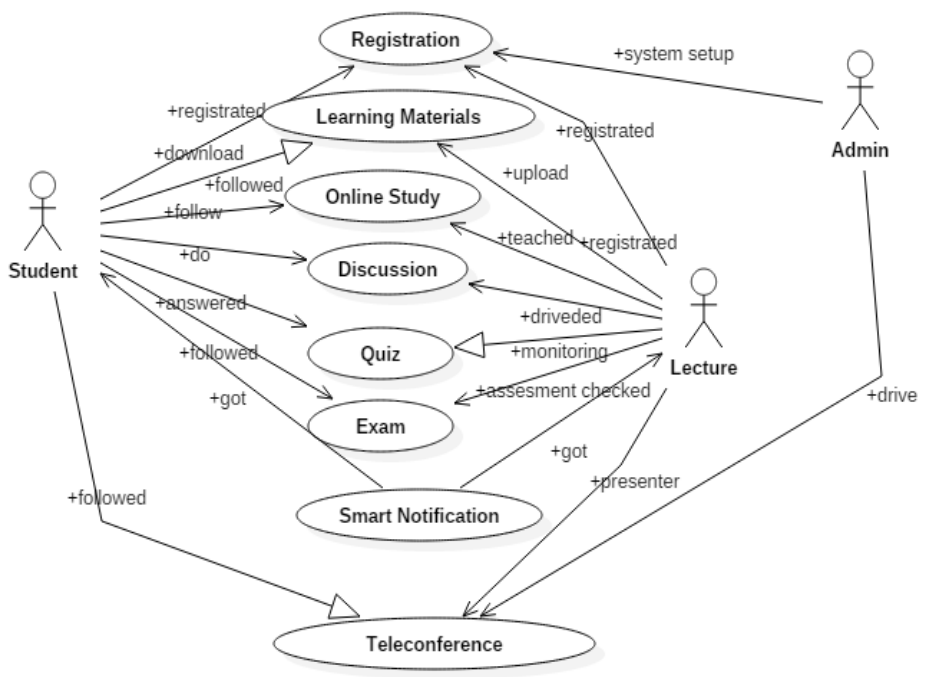

Fig. 2. Use Case Diagram UML.

The figure above shows the relationship between actor student, lecture and admin that interact in MCL system. They interact in system registration, learning materials, online study, discussion, quiz, exam and teleconference.

\subsection{Activity Diagram}

This diagram shows the existence of work flow or activity of a system, in MCL there are some activity process which is described in the form of activity diagram as shown in picture below:

1) Login Activity

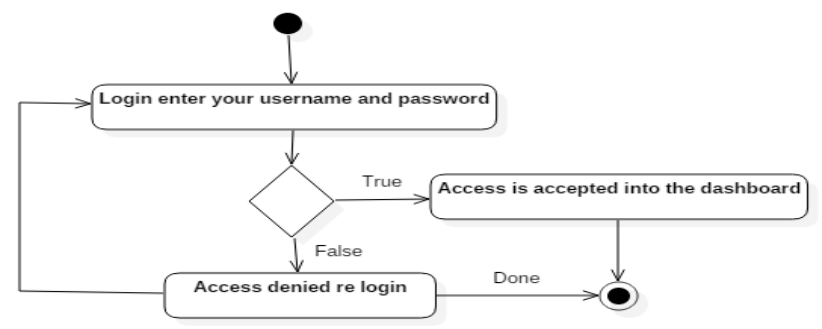

Fig. 3. Activity Diagram Login.

The login activity diagram above shows the user process must enter the username and password into the system which will then be validated, if the username and password are appropriate then access is accepted and go to the dashboard page but if not appropriate will return to the login page. 
2) User Registration Activity

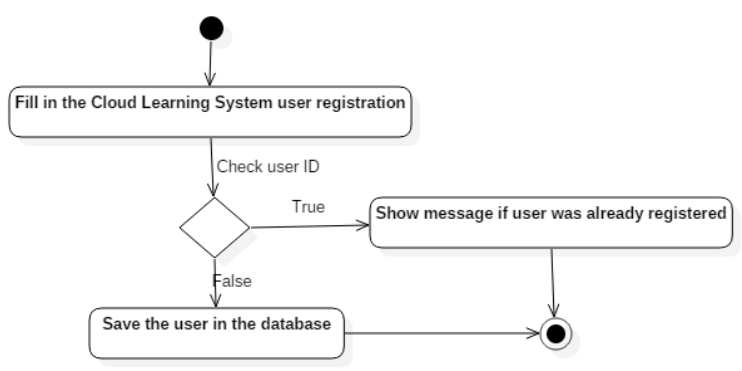

Fig . 4. Activity Diagram Registrasi User.

Activity diagram in Fig 4 above shows the user registration process in MCL if user already exists then there will be notification if user have registered but if not yet then user data will be stored in database.

3) Lecturer Registration Activity

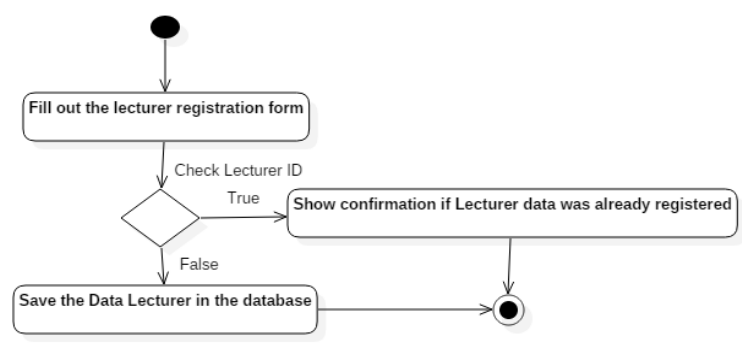

Fig .5. Activity Diagram Registrasi Dosen.

The figure above activity diagram shows lecturer registration process in MCL if lecturer data already exists it will show confirmation if data have been registered but if no then lecturer data will be stored in database.

\subsection{Sequence Diagram}

This diagram shows the interaction between objects and an indication of the relationship between the objects. The design of MCL sequence diagram shown as shown below:

1) Sequence diagram of user interaction 


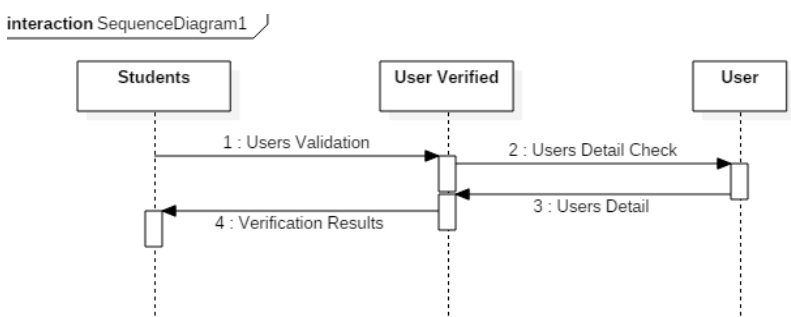

Fig .6. Sequence Diagram User Interaction.

Sequence diagram in fig 6 above shows the interaction of students who do login then MCL will do the user verification and the results will be seen by the students.

2) Sequence diagram of online study interaction

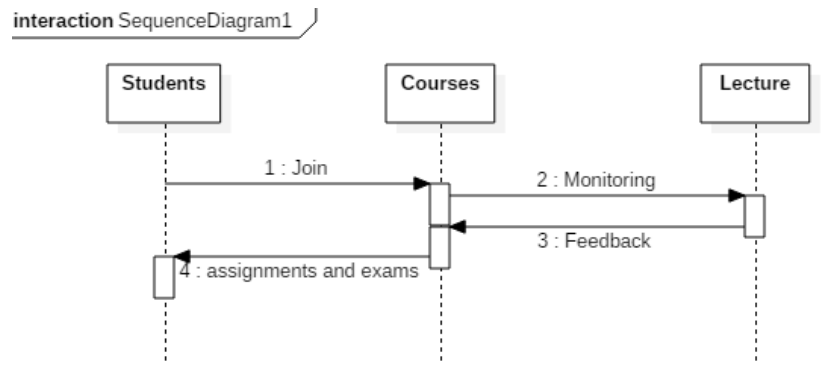

Fig .7. Sequence Diagram Online Study Interaction.

Sequence diagram in fig 7 above shows the interaction of students studying in MCL of a course, Lecturer conducts monitoring in the learning.

\subsection{Class Diagram}

Class diagram is a class that describes the structure and explanation of classes, packages, and objects as well as relationships with each other such as containment, inheritance, associations, and others. Class diagrams have 3 parts of names, attributes and operations. UML provides inter-class relationships (Association (Static relationships between classes), Aggregation (relationships of the whole object), Generalization (relation of multiple subclasses to super classes), Dependency (connectedness of each class.). MCL class diagram shown as the picture below: 


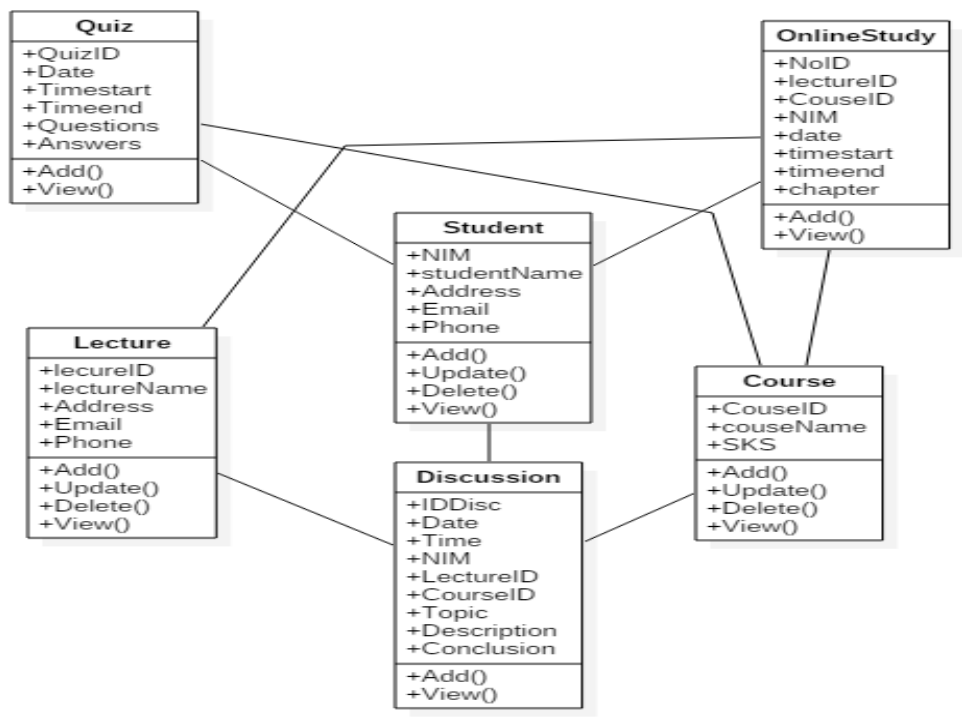

Fig. 8. Class Diagram MCL.

The class diagram in fig 8 above shows the relationship between student, lecture and course classes that have relationships into class discussions, online studies and quizzes. Six classes above daling related in forming MCL design.

\section{Conclusion}

After discussing about MCL design using UML hence can be concluded as follows:

1) Mobile Learning is a new paradigm in the world of online learning, Learning with smartphone devices evolve as more and more gadget usage by students.

2) Mobile Cloud Learning (MCL) is a combination of cloud computing technology combined with the optimization of gadgets in learning.

3) MCL design using UML is very helpful in generating object-based design that will help the process of making application program. 


\section{References}

[1] F. Sharmila, Nisha Jebaseeli, "Enhancing M-Learning System Using Cloud Computing. International Journal of Computer Sciences and Engineering," vol. 4, no. 01, 2016.

[2] P. P. E. A. Ms. Shubhangi Ashok Kolte1, "A Survey - Cloud Computing, International Journal of Advanced Research in Computer and Communication Engineering," vol. 5, no. 4, 2016.

[3] S. K. Behera, "M-Learning: A New Learning Paradigm, International Journal on New Trends in Education and Their Implications," vol. 4, no. 2, 2013.

[4] W. Wains, S., \& Mahmood, "Integrating m-Learning with e-learning. Paper presented at the 9th ACM Special Interest Group for Information Technology Education (SIGITE'08),” 2008.

[5] A. B. Nassuora, "Students Acceptance Of Mobile Learning For Higher Education In Saudi Arabia," Am. Acad. Sch. Res. J., vol. 4, 2012.

[6] Esam Idris K. Al Hassan, "Mobile Learning New Technique to Contribute the Development of Distance Learning Courses, as views from Specialists of Information and Instructional Technology in Sudanese Universities," J. Educ. Hum. Dev., vol. 4, pp. 269-276, 2015.

[7] K. S. Bhavnesh Kumar, "Testing UML Designs using Class, Sequence and Activity Diagrams, International Journal for Innovative Research in Science \& Technology," 2015, vol. 2, no. 3.

[8] S. Lee, "Unified Modeling Language (UML) for Database Systems and Computer Applications,International Journal of Database Theory and Application," 2012, vol. 5.

[9] A. P. Shevali Agarwal, "A Study of Agile Software Development," Int. J. Eng. Sci. Res. Technol., 2013. 